\title{
VIBROACOUSTIC METHODS OF IMAGING IN SELECTED TEMPOROMANDIBULAR JOINT DISORDERS DURING MOVEMENT
}

\author{
Pawel ŁYŻWA*, Maciej KŁACZYŃSKI**, Piotr KAZANA**** \\ *, ** AGH University of Science and Technology, Faculty of Mechanical Engineering and Robotics \\ Adama Mickiewicza 30, 30-059 Kraków, Poland, \\ e-mail: * palyzwa@gmail.com, ** maciej.klaczynski@agh.edu.pl \\ *** Piotr Kazana Cabinet of Dental Physiotherapy, \\ Friedleina 6/2, 30-009 Kraków, Poland, e-mail: p.kazana@op.pl
}

\begin{abstract}
Temporomandibular joints are part of the stomatognathic system and play an important role in chewing, swallowing and speech articulating and expressing emotions. Unfortunately, they often do not work properly. Occasional disorder, postural defects, increased muscle tone bearing down due to stress deprivation through such parafunctions as clenching and grinding teeth, long-term chewing gum, nail biting or chewing lips and cheeks can lead to the appearance of dysfunctions in the temporomandibular joints. Analysis of vibrations caused by dysfunctions enables a more accurate diagnosis and an objective way of monitoring the treatment process. The article presents the results of pilot studies carried out in this area by Authors on a group of 13 people ( 9 women and 4 men) suffering from various diseases within the stomatognathic system. Particular attention was paid to the problems associated with vibroacoustic registration of temporomandibular joint cracks that occurred during the determination of the test methodology.
\end{abstract}

Keywords: Temporomandibular joint disorders, vibroacoustic diagnostics, medical imaging

\section{METODY WIBROAKUSTYCZNE W OBRAZOWANIU WYBRANYCH SCHORZEŃ PRACY STAWU SKRONIOWO-ŻUCHWOWEGO}

Streszczenie

Stawy skroniowo-żuchwowe są elementem układu stomatognatycznego i pełnią ważną rolę w procesach żucia, połykania, artykulacji dźwięków i wyrażania emocji. Zaburzenia okluzyjne, wady postawy ciała, wzmożone napięcie mięśni unoszących żuchwę spowodowane rozładowywaniem stresu przez takie parafunkcje jak zaciskanie i zgrzytanie zębami, długotrwale żucie gumy, obgryzanie paznokci czy przygryzanie warg i policzków mogą doprowadzić do pojawienia się dysfunkcji w obrębie stawów skroniowo-żuchwowych. Artykuł przedstawia efekty badań pilotażowych przeprowadzonych w tym obszarze przez Autorów na grupie 13 osób (9 kobiet i 4 mężczyzn) cierpiących na różne schorzenia w obrębie układu stomatognatycznego. Szczególną uwagę zwrócono na problemy związane z wibroakustyczną rejestracją trzasków stawów skroniowo-żuchwowych, które pojawiły się podczas ustalania metodologii badań.

Słowa kluczowe: schorzenia stawu skroniowo-żuchwowego, diagnostyka wibroakustyczna, obrazowanie medyczne

\section{INTRODUCTION}

One of the symptoms of temporomandibular joints disturbance is the formation of vibroacoustic phenomena. Most often these are sounds of the nature of clicking, knocks or friction. They are quite common and do not always require treatment $[4,6]$. The causes of vibroacoustic symptoms within the temporomandibular joints are complex, but they always involve loss of coordination between the disc and the condyle (head of mandible) during its movements and change in tension on rumen muscles. The most common cause of this condition is bruxism (unconscious stress relieving by clamping, grinding of teeth) and habits such as nail biting, heavy gum chewing, unilateral chewing of foods and improper posture $[9,13]$.

The genetic predispositions, injuries, unstable short-circuiting of teeth and changes in the surface and chewing mechanics as a result of prosthetic or orthodontic treatment are also important causes of disorders in the temporomandibular joints. At the same time, improper functioning of the joint may have a negative impact on the chewing process and increase tooth wear [2, 6, 12].

There are various types of temporomandibular joint disorders. Each of them, except for painful acute dislocations of the articular disc, is connected with various vibrations [7]. 
Acoustic phenomena occur most frequently during the previous displacement of the disc. More rarely, the dislocation of the disc in the medial direction may occur during the restoration movement. The following progression is observed in the diseases of the temporomandibular joint:

- sporadic crashes in the irregular displacement of the articular disc,

- cracks in the regular dislocation of the disc without blocked, connected to the path of the mandible movement - one or two cracks on the movement,

- blocking conditions of the disc,

- degenerative disorder of the joint - frequent, irregular cracks caused by friction.

Disorders in the joint can occur on one side and on both sides. In addition, unilateral the condition may cause subluxation (dislocation of joint surfaces with partial loss of mutual contact) in the opposite joint, which also causes crackling [1].

Researchers do not agree whether a healthy joint can also be a source of acoustic phenomena [12]: they maintain that it is not, while in a certain article [8] authors talk about disturbances emitted by the patient. The noise comes from the measuring path, but also results, for example, from the contact of teeth and lips, so there is no source in the joint itself. In addition, cracks in the joint may occur when the joint is moved out of the normal functioning range of healthy people. Course of changes in the temporomandibular joint is difficult to predict. Lesions can get worse, but the body can also adapt and then it does not require treatment [12].

Several classical methods are used to diagnose temporomandibular joint condition [5,10,11,14,15]. Starting with a conversation with the patient, which provides information on whether there are limitations in performing daily activities and pain, which may have a different source (muscles, teeth). Then a visual evaluation of the movements of the mandible - defining their range and trajectory - and palpation - is made by touch. X-ray examinations, magnetic resonance imaging or computed tomography are also useful. However, they are still less available and above all, not recommended during the rehabilitation process (too frequent $\mathrm{X}$ rays of the head and neck area).

The aim of this research is to test the suitability of various vibroacoustic methods of registering temporomandibular joints in terms of their usefulness in monitoring the progress of treatment. The solution should be as unobtrusive as possible for the patient, enable simultaneous recording of signals from both joints and allow to determine at what stage of the movement vibroacoustic events occur.

\section{RESEARCH MATERIAL}

In this pilot studies, 13 people ( 9 women and 4 men) with various medical condition were examined, which were summarized in Table 1 . The AO patient participated only in preliminary studies, KP and PL were examined by all methods, while the rest were only by binaural microphones and accelerometers.

Based on a physiotherapeutic assessment, patients were divided into three groups, depending on the mechanism of acoustic phenomena in their joints:

1. displacement of the disc in any direction - diskligamental crack,

2. contact of the condyle with the articular node bone crack,

3. degenerative joint surface changes and dehydration of the disc - creations, friction.

One of examined patients belongs simultaneously to two groups, because the cause of the glitches in her joints is different for each side.

Table 1. Causes of vibroacoustic symptoms in the

\begin{tabular}{|c|c|c|}
\hline \multicolumn{3}{|c|}{ examined patients - medical assessment } \\
\hline Patient ID & $\begin{array}{c}\text { left joint } \\
\text { disk- } \\
\text { ligamentous (1) }\end{array}$ & right joint \\
\hline KP & $\begin{array}{c}\text { disk- } \\
\text { ligamentous (1) }\end{array}$ & - \\
\hline AO & $\begin{array}{c}\text { disk- } \\
\text { ligamentous (1) }\end{array}$ & - \\
\hline PL & - & degenerative (3) \\
\hline LB & no crackle & no crackle \\
\hline MK & no crackle & no crackle \\
\hline PK & - & disk- \\
\hline NG & ligamentous (1) \\
\hline MKoz & degenerative (3) & bone (2) \\
\hline AS & disk- & disk- \\
\hline BZ & ligamentous (1) & ligamentous (1) \\
\hline Du & no crackle & no crackle \\
\hline MKocj & disk- & - \\
\hline MN & digamentous (1) & \\
\hline & & - \\
\hline
\end{tabular}

Patients were examined in a physiologically correct sitting position, controlled by a physiotherapist. The order of exercises performed in the full range of motion was decided on:

- three-click taps used to synchronize signals,

- slow opening and closing of the mouth,

- slow movements from side to side, stopping in the rest position,

- slowly protruding the mandible and returning to the rest position,

- three quick openings and closings of lips,

- fast sideways movements - three times in each direction,

- three times quick mandibular protrusions, each time back to rest position.

In the initial phase of the study, an attempt was made to record the snap of the joints during 
chewing jelly beans. The recorded signals contained disturbances related to the contact of the teeth, which complicates later analysis with complex movements of the mandible. In addition, chewing gum jelly takes a relatively long time, which is not without significance for the condition of the patient's joint. Therefore, it was decided to give up this exercise. The number of exercises is due to the fact that the occurrence of clicks depends on the direction and speed of movement. At the same time, the occurrence of a snap may depend on the degree of warming up of the muscles that change their behavior during exercise. To increase the reproducibility of the studies, the preparation of motion animations along with a sound signal was considered. This would facilitate the subsequent analysis of the collected signals thanks to the constant time of each exercise. However, it turned out that repeating the exercises at an imposed rate may pose a problem for patients. Earlier practice of the sequence may change the behavior of the joint, so this option was abandoned. Eventually, patients imitated the physiotherapist's movements "live". Each of the measurements was accompanied by video recording of the lower part of the face using Nikon D3100. Registered image provides information not only about the moment when the movement occurred, but also what was the scope of the movement and whether additional muscles (e.g. lips) were involved in the performance of the exercise due to physiological limitations.

\section{MEASUREMENT TECHNIQUE}

\subsection{Apparatus}

Initial research was carried out in a small anechoic chamber of AGH University of Science and Technology in Kraków using G.R.A.S 40 AE measurement microphones with $50 \mathrm{mV} / \mathrm{Pa}$ nominal sensitivity. The further measurement system consisted of NORSONIC 1201 preamplifier, G.R.A.S 12 AA amplifier and M-Audio Profire 610 card connected to the computer. Signals were recorded in Adobe Audition 3.0 with a sampling rate of $f s=44.1 \mathrm{kHz}$. They were intended to check whether it is possible to register the quietest glitches by air. Measurements were also made with the 3M TM Littmann 3200 electronic stethoscope. Device has a frequency response of up to $2 \mathrm{kHz}$, works with a sampling frequency of $f s=4 \mathrm{kHz}$. When exporting signals from StethAssist to WAVE files filtration with the widest possible bandwidth of $50-500 \mathrm{~Hz}$ ("Extended Range") has been used.

Because the above methods revealed a number of disadvantages (which are presented in next chapters), only three patients were examined in this way, and further tests were carried out using Soundman OKM II R Studio binaural microphones with $5 \mathrm{mV} / \mathrm{Pa}$ nominal sensitivity and $20 \mathrm{~Hz}-20 \mathrm{kHz}$ frequency band connected through a dedicated A3 adapter for to Intel High Definition Audio sound card embedded in a laptop. Signals were recorded in the REAPER digital audio workstation with a sampling frequency of $f s=44.1 \mathrm{kHz}$ with the highest amplification possible on the sound card. The last applied recording method used two 3-sided piezoelectric PCB $356 \mathrm{~B} 18$ vibration transducers with a frequency range of $0.5-3000 \mathrm{~Hz}$ and $1 \mathrm{~V} / \mathrm{g}$ sensitivity, mounted on a specially prepared headband. The further measurement path consisted of a multi-channel digital recorder LMS SCADAS MOBILE equipped with measuring cards VM8-E and VM8 together with the LMS Test.Xpress 7A software. The sampling frequency was $f s=10240 \mathrm{~Hz}$.

\subsection{Recording with measurement microphones in an anechoic chamber}

Three patients' crackles were recorded using measurement microphones. Study was carried out in a small anechoic chamber at the AGH University of Science and Technology. The series of exercises was performed four times: with the expander spreading the patient's lips (revealing teeth) and without it; first under the control of the current physiotherapist in the chamber, later by yourself. As these were the first attempts to register, the measurement path was not calibrated and the gain was adjusted depending on the level of glitches during the measurement. Satisfactory results were obtained, the crackling was clearly heard on the recordings (see Fig. 1). The possibilities of registering in this way, however, are quite limited, due to the necessity of staying in an anechoic chamber. The disadvantage of this method is also crosstalk between channels and the fact that loud breath can mask the quiet crackling from the joints. To avoid these problems, an attempt was made to use in-ear microphones.

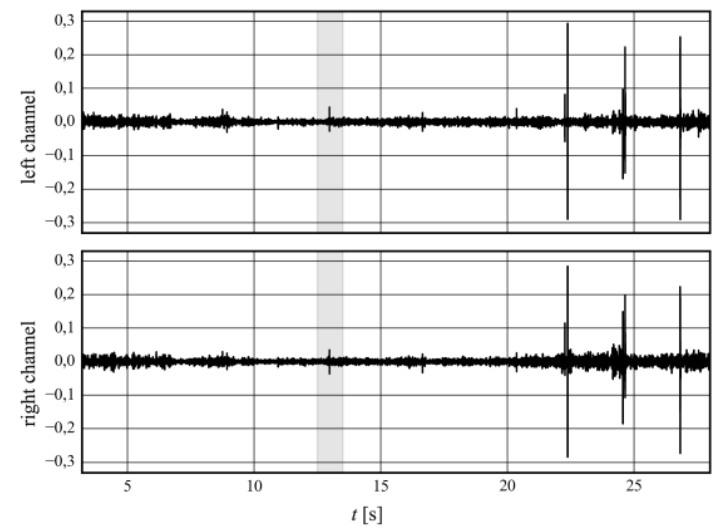

Fig. 1. Example of a signal recorded with measuring microphones in the anechoic chamber (gray area - crackle)

\subsection{Measurements with an electronic stethoscope}

In addition, an anechoic chamber was also investigated to record snapshots using the $3 \mathrm{M}$ TM Littmann 3200 electronic stethoscope. It is a singlechannel device, so it does not allow to determine which side the sound comes from, which does not 
exclude the possibility of examining whether this type of transducer is suitable for registration sounds coming from the temporomandibular joint. During the test, the physiotherapist put a stethoscope to the joint and the patient performed a set of exercises. Each measurement began with a finger tap on the stethoscope that was visible in the camera. An important problem was the lack of good contact of the stethoscope membrane with the skin. An attempt was made to use a gel for ultrasound examinations, which slightly improved the results. It was also noted, according to studies [8], that when the patient presses the device on his face, a better result is obtained than when the other person does it. However, though this variability of pressure inherent in the stethoscope being held by a human introduces distortions difficult to predict, depending on a particular sample, degree. It was decided to give up this method in favor of sensitive vibration transducers mounted on the headband.

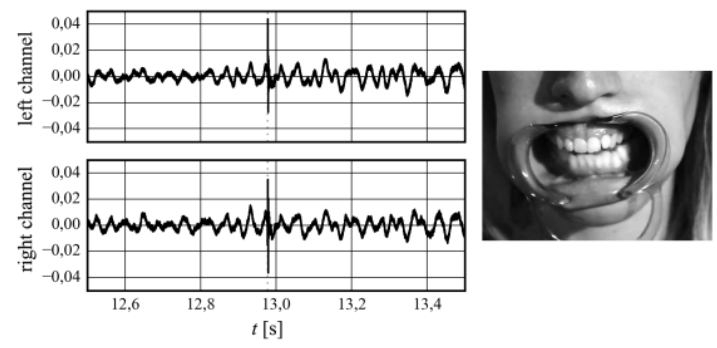

Fig. 2. An example of a crack - the approximation of the area marked in Fig. 1 together with the image from the camera at the moment of the crack
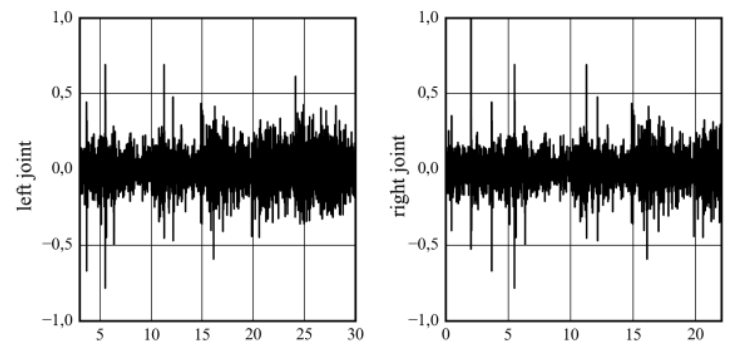

Fig. 3. Examples of signals recorded with a stethoscope

\subsection{Measurements with binaural microphones}

The microphones have been placed in the ears in the opposite direction than usually during binaural recordings, i.e. transducers directed inside the ear. Due to the close-up of the transducer's proximity to a sound source, the signal-tobackground ratio was increased. Hearing protectors were considered to isolate microphones from sounds of the surroundings, but they hindered stable positioning of the microphones in the ear (their cables were tight) and caused great discomfort during the exercise, which excluded them from use in the research.

\subsection{Measurements by accelerometers}

The last method of recording glitches uses piezoelectric vibration transducers. It is not possible to attach the transducer directly to the bone in a non-invasive way, and sticking it to the skin would involve significant nuisances, so it was decided to mount it by holdfast. Sponges and casing components were removed from old headphones and two PCB 356B18 accelerometers (see Fig. 6) were affixed to the bracket prepared in this way. Measurements were made with transducers placed on the temporomandibular joint (Fig. 7a). A different position of accelerometers was also examined - behind the ears on mastoid process (Fig. $7 \mathrm{~b})$. It is more stable, because the accelerometer is not on the pond in motion, but then we register vibrations transmitted from the joint through the bone. Both registrations were performed simultaneously with the recording of the microphones signal.
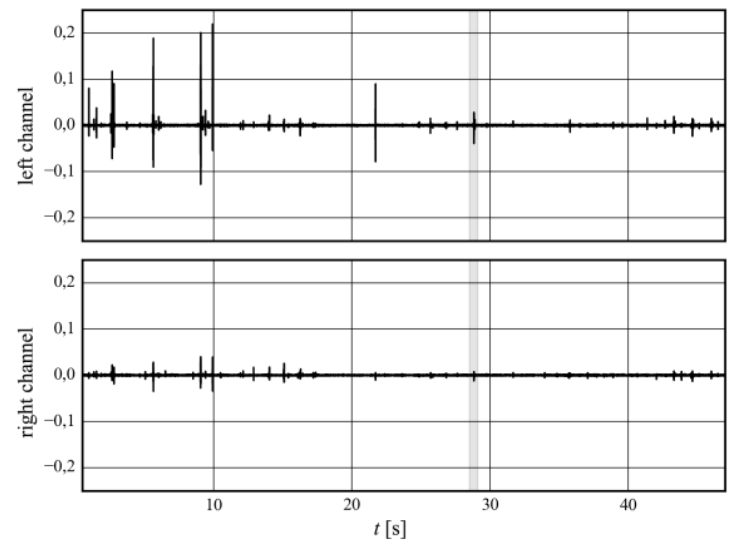

Fig. 4. Signal recorded with binaural microphones outside the anechoic chamber MN patient (gray area - crackle)

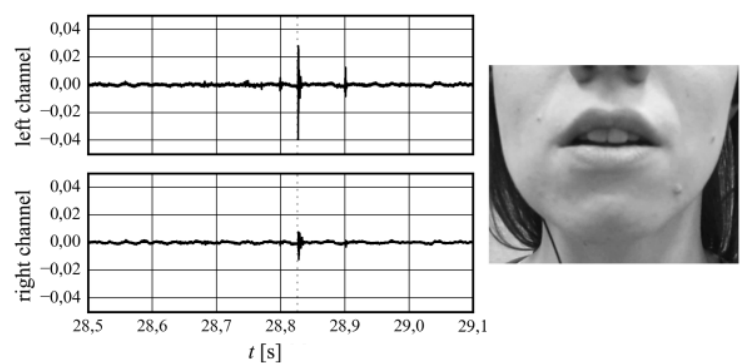

Fig. 5. Crackle when mandible is extended approximate the area marked in Fig. 4 and the image from the camera at the time of its occurrence

\section{ANALYSIS OF MEASUREMENT DATA}

Acoustic phenomena originating from the temporomandibular joint have an impulsive character and their duration is up to $15 \mathrm{~ms}$. Therefore, the variability of parameters and spectrum of the signals over time was studied. The signal was divided into frames every $35 \mathrm{~ms}$ (with 
overlapping), with the length as in Table 2, depending on the sampling frequency.

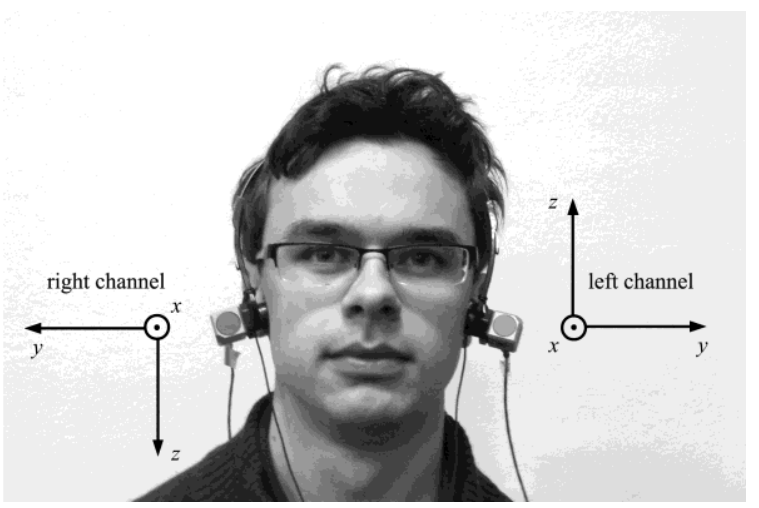

Fig. 6. Vibration transducer axis identification
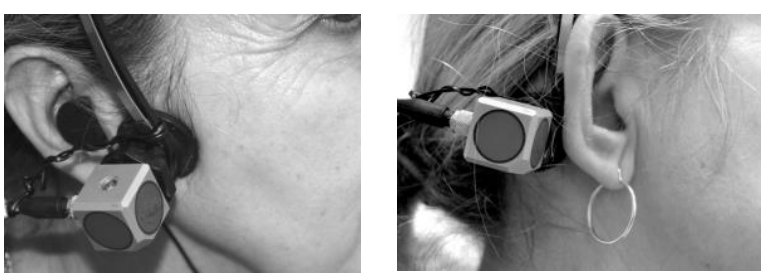

Fig. 7. Location of accelerometers during measurement a) on the joint $b$ ) on the mastoid process
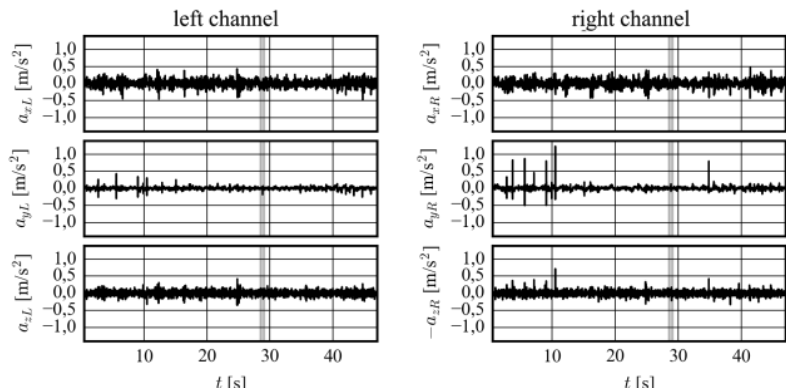

Fig. 8. Signal registered with accelerometers patient MN, transducers on the joints, simultaneous measurement with the registration shown in Fig. 4.
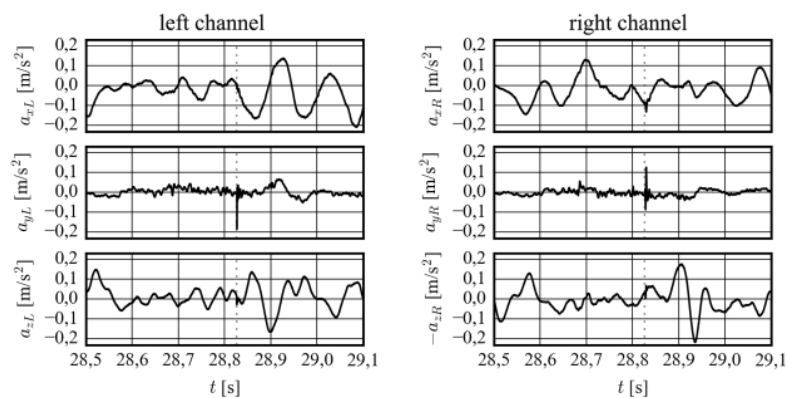

Fig. 9. Crackle when the mandible is extended approximate the area marked in Fig. 8.

It was decided to examine the following local parameters of the digital signal $x[n]$ :

- peak value

$$
P E A K=\max (|x[n]|)
$$

$$
R M S=\sqrt{\frac{1}{N} \sum_{n=0}^{N-1} x^{2}[n]}
$$

- crest factor

$$
\text { CREST }=\frac{P E A K}{R M S}
$$

In addition, frequency analysis of framed signals was performed using a discrete Fourier transform and a Blackman window:

$$
X[k]=\sum_{n=0}^{N-1} x[n] \exp \left(-2 \pi j \frac{n k}{N}\right)
$$

Table 2. Length of signal frames

\begin{tabular}{|c|c|c|}
\hline $\mathbf{f}$ [kHz] & M [sample] & M/fs [ms] \\
\hline 44100 & 2048 & 46,7 \\
\hline 10240 & 512 & 50 \\
\hline 4000 & 256 & 64 \\
\hline
\end{tabular}

During the analysis the signal filtration process was used. Filters with finite impulse response (FIR) were decided, because their higher computational complexity is not a problem in this case, but they do not introduce phase distortions. In these filters, designed using the window method, an almost flat amplitude characteristic in the bandwidth and high damping in the barrier band were obtained.

\subsection{Signal from microphones remote from the head}

A 1001st order FIR filter was used to analyze the signal with a bandwidth of $120-4000 \mathrm{~Hz}$. It has been designed using the Blackman window. Figure 10 contains parameter graphs (RMS, PEAK, CREST FACTOR) depending on time. Vertical lines made of dots are in the places where the crackles occur. Often there are no differences in the levels between channels, which would allow to determine from which side the phenomenon originated. It also turns out that all the crackles correspond to the local maxima, but the inverse relationship does not occur - the maxima of the parameters can also mean the tapping of teeth, swallowing saliva etc. Therefore, it was decided to examine the spectra of these events, determining their positions in the signal by listening and comparing with the video image.

Figure 11 contain spectra of unfiltered signal fragments (frames) that contain crackle and distortions. We notice that the pops have more energy in the $200-500 \mathrm{~Hz}$ band than interference. This indicates the potential usefulness of microphones in the study of the issue. 

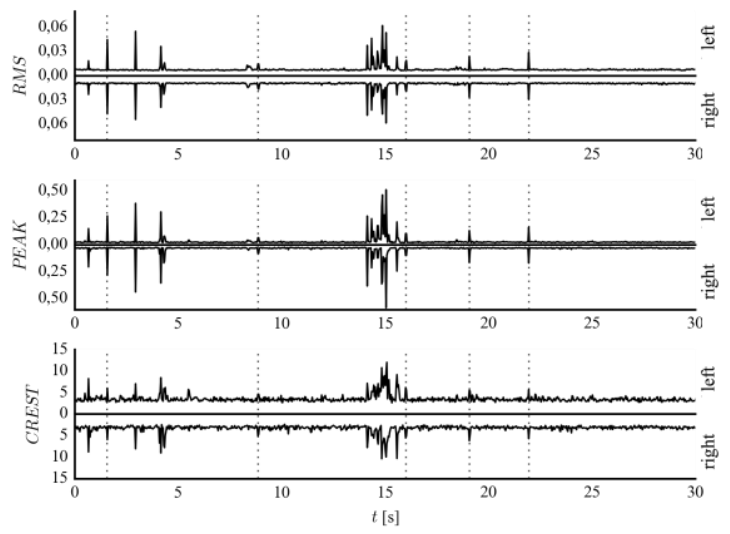

Fig. 10. Parameters of signals recorded with microphones away from the head - patient AO

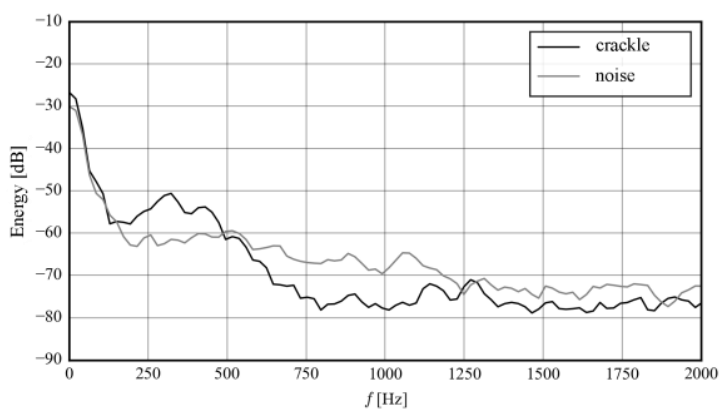

Fig. 11. Comparison of the average spectra of events recorded in the anechoic chamber with microphones remote from the head

\subsection{Signals from a stethoscope}

As in the case of signals recorded with microphones in an anechoic chamber, it was decided to use a filter. Due to the low sampling rate $(4000 \mathrm{~Hz})$, only $101 \mathrm{st}$ order FIR filter was used, designed in similarly to the one described in the previous chapter. An attempt was made to compare the results obtained during the measurement with and without using the gel used for ultrasound warheads. From the parameters in Figures 12 and 13 it can only be hypothesized that use of gel increases energy transfer, but it is difficult to assess if it would increase the effectiveness of the measurement. During both registrations the patient's joint did not make any audible noises. It was decided not to repeat the measurements, because it was not planned to use single-channel devices ultimately.

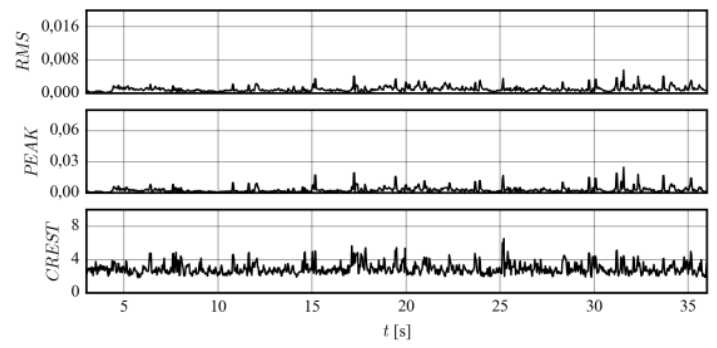

Fig. 12. Parameters of cracks signal recorded without ultrasound gel - patient PL

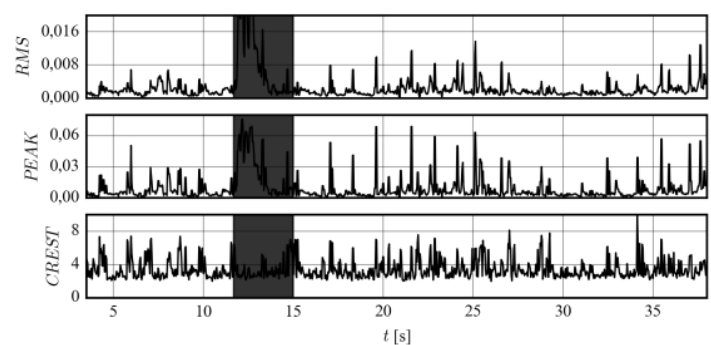

Fig. 13. Parameters of cracks signal recorded with ultrasound gel - patient PL. The marked area contains the moment in which the patient spoke

\subsection{Signals from binaural microphones}

Signals from the binaural microphones did not contain significant external disturbances even in the case of recordings outside the anechoic chamber, so they were discontinued. Figure 14 contains patient parameter graphs, the crackle of which occurs unilaterally. The page on which the phenomenon appears is very well visible on them (see Fig. 15).
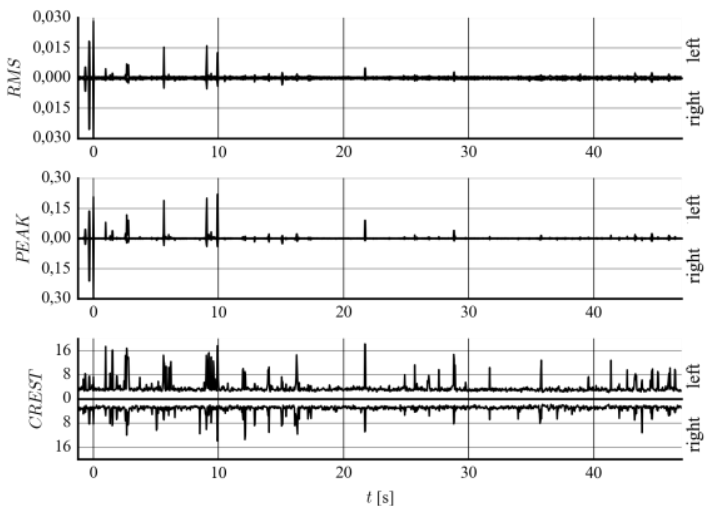

Fig. 14. Parameters of signals from microphones recorded outside the anechoic chamber - patient $\mathrm{MN}$ with unilateral disturbances

The next figure refers to $\mathrm{BZ}$ patient, with whom the crackle occurs on both sides, but there is more impulse interference in the recording (Fig. 15). By comparing the spectra, it can be seen that these disturbances have relatively more energy at higher frequencies and a higher peak factor coming from the temporomandibular joint (see Fig. 16).

\subsection{Signals from accelerometers}

Signals from accelerometers have components with the lowest frequencies that are related to the movement of the exercises. In order not to disturb the measurement, they were filtered with a $50 \mathrm{~Hz}$ cut-off filter. An 555th order FIR filter was used, designed by the window method (Blackman). Figures $17 \div 22$ contain time course of analyzed parameters, grouped by axes, for two different transducer positions. We note that the energy is transmitted preferably along an axis perpendicular to the transducer application face (Y). Signals from other directions also contain information about crackles, but having much worse quality than on the $\mathrm{Y}$ axis. Placing the transducer behind the ear makes 
it difficult to determine the side from which the sound comes from (decreases the difference in levels between channels), but also reduces the level of interference caused by the tapping of teeth against, which results from the construction of the skeletal system of the head.
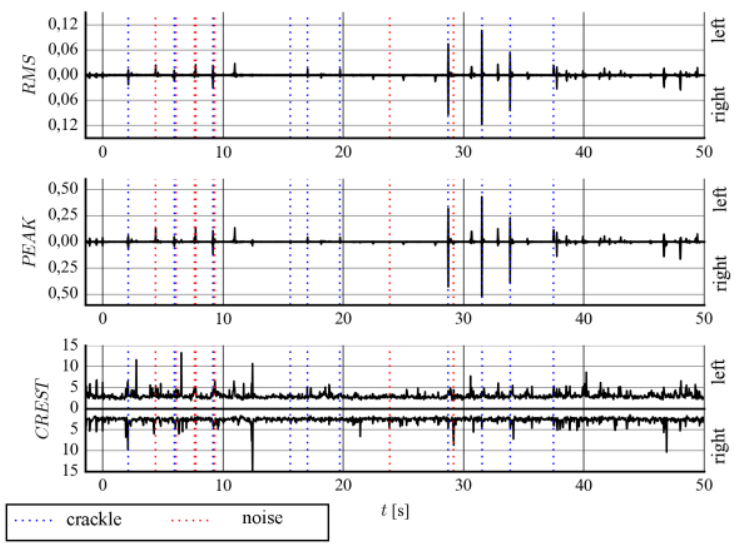

Fig. 15. Parameters of signals from binaural microphones. Recording outside the anechoic chamber - patient BZ

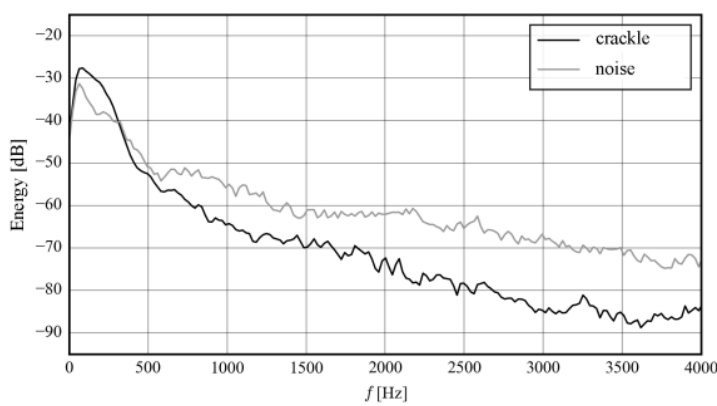

Fig. 16. Comparison of the average spectra of events. Recording outside the anechoic chamber patient BZ
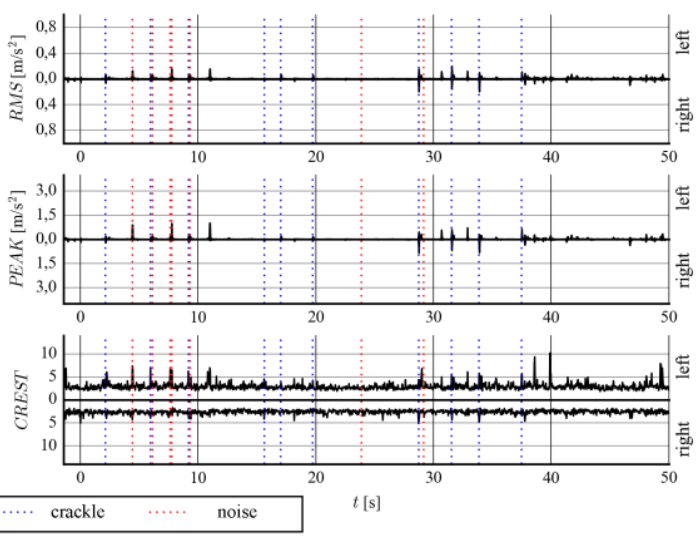

Fig. 17. Parameters of the signal from accelerometers (BZ patient) - transducer on the joint, $\mathrm{X}$ axis

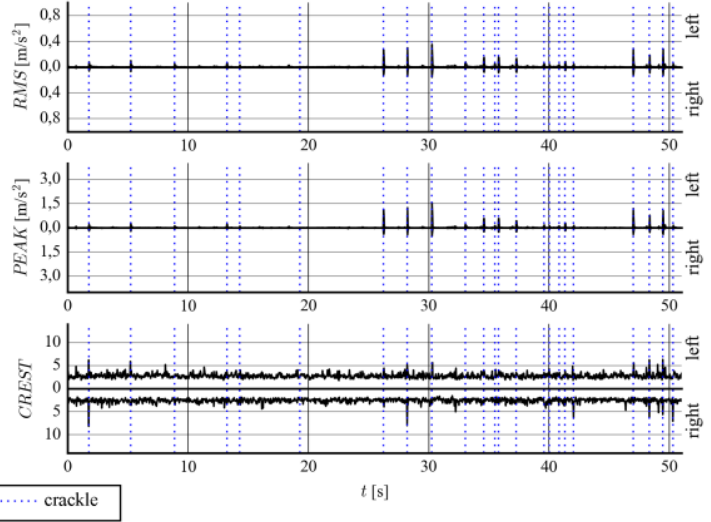

Fig. 18. Parameters of the signal from accelerometers (BZ patient) - transducer behind the ear, $\mathrm{X}$ axis
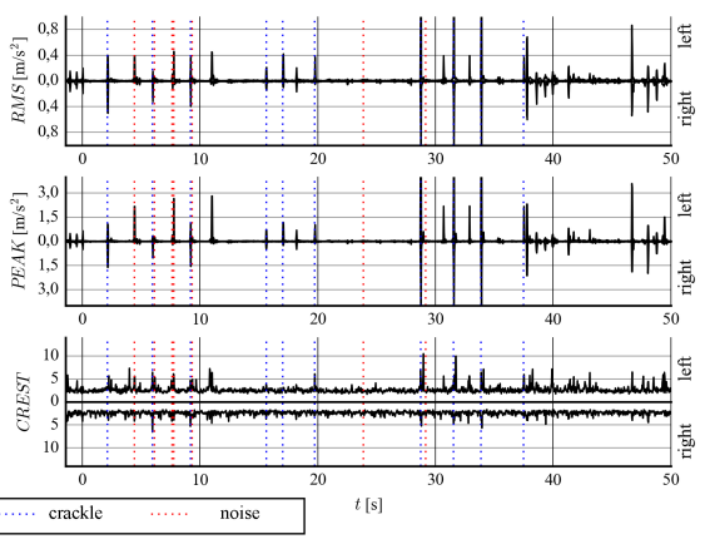

Fig. 19. Parameters of the signal from accelerometers (BZ patient) - transducer on the joint, $\mathrm{Y}$ axis
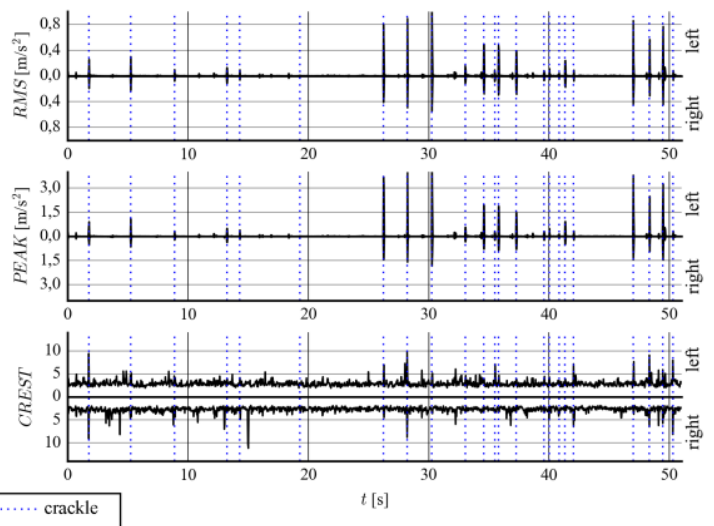

Fig. 20. Parameters of the signal from accelerometers (BZ patient) - transducer behind the ear, $\mathrm{Y}$ axis

For $\mathrm{Y}$ axis, perpendicular to the plane of the temporomandibular joint, averaged spectra were plotted (Fig. 23). Similarly, as in the case of recording with other methods the crackles occurs in the band up to several hundred hertz, and the disturbances occur more in $500-1000 \mathrm{~Hz}$ band. This means that the accelerometer test yields the expected results in both tested transducer positions. It is therefore the most appropriate method for 
studying the acoustic phenomena of the temporomandibular joints mandibular - the signal contains information needed for analysis at the smallest possible level of adverse information.

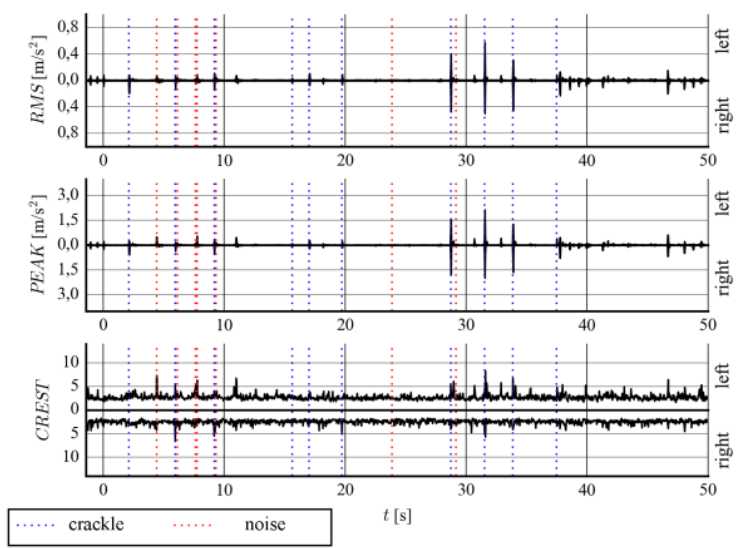

Fig. 21. Parameters of the signal from accelerometers (BZ patient) - transducer on the joint, $\mathrm{Z}$ axis

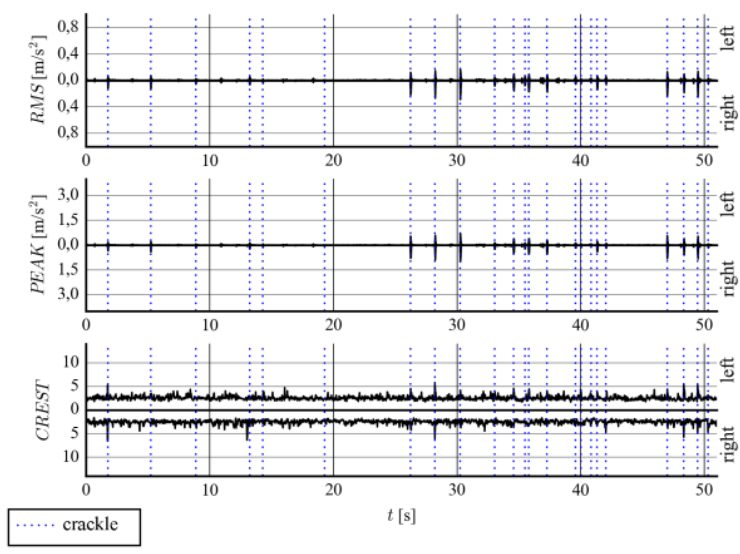

Fig. 22. Parameters of the signal from accelerometers (BZ patient) - transducer behind the ear, $\mathrm{Z}$ axis

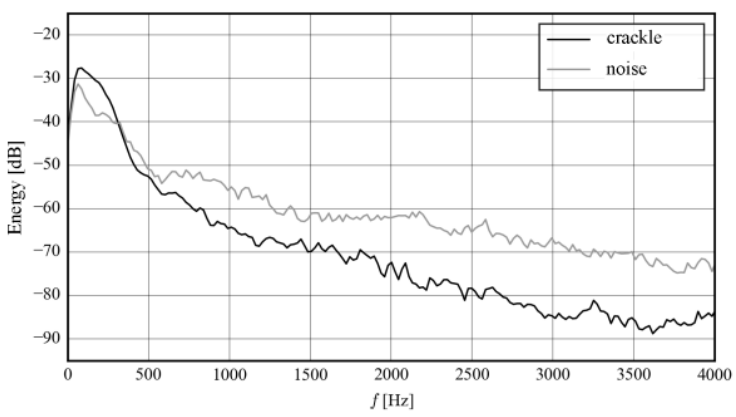

Fig. 23. Comparison of average event spectra for a joint accelerometer (BZ patient), $\mathrm{Y}$ axis

\section{CONCLUSION}

This paper focuses on searching for the optimal method of registering temporomandibular joint fractures during various stages of treatment. Four different methods of registration of these events have been proposed and verified. Both recording with ear microphones and vibration transducers allows to evaluate the results of treatment - this can be done by listening to recordings at various stages and comparing the values of simple parameters (e.g. energy parameters proposed in the work: RMS, PEAK, CREST FACTOR). Binaural microphones are promising transducers for studying acoustic phenomena from the temporomandibular joint. Recording of crackles with binaural microphones can take place outside the anechoic chamber while maintaining the appropriate signalto-noise ratio. This technique can work well in the physiotherapist's office, especially since it does not require specialized equipment, which is much less expensive than the method using accelerometers. However, they require careful use and control during registration, as there are many factors that may decide about difficulties in later analysis: interference with wireless communication (mobile phones), ambient noise and loose microphone placement in the ear that may interfere with measurement during movement.

The work is the result of pilot studies carried out by the authors. The next steps will be directed to the connection of determining the position of the mandible based on the image from the camera with vibroacoustic data.

\section{REFERENCES}

1. Baron S, Krush R, Bindek $\mathrm{K}$. Crackles in temporomandibular joints, e-Dentico, 2005; 3(7): 4851. Polish.

2. Bindek-Sypień K, Baro S, Sypień M. Causes of reciprocal clicks due to the temporomandibular disc displacement: Clinical function analysis and axiographic evaluation, Protetyka Stomatologiczna, 2010; LX(4): 252-259, Polish.

3. Canser Yilmaz Demir, Omer Faruk Kocak, Nazim Bozan, Muhammet Eren Ersoz, Halit Demir, Is There a Role for Oxidative Stress in Temporomandibular Joint Disorders? Journal of Oral and Maxillofacial Surgery, 2018; 76(3): 515-520.

https://doi.org/10.1016/j.joms.2017.11.004

4. Chih-Ling Chang, Ding-Han Wang, Mu-Chen Yang, Wun-Eng Hsu, Ming-Lun Hsu, Functional disorders of the temporomandibular joints: Internal derangement of the temporomandibular joint, The Kaohsiung Journal of Medical Sciences, 2018; 34(4): 223-230.

https://doi.org/10.1016/j.kjms.2018.01.004

5. Manfredini D, Guarda-Nardini L, Ultrasonography of the temporomandibular joint: a literature review, International Journal of Oral and Maxillofacial Surgery, 2009; 38(12): 1229-1236. https://doi.org/10.1016/j.ijom.2009.07.014

6. Gunnar E. Carlsson, Chapter 13: Temporomandibular Joint Disorders In: Functional Occlusion in Restorative Dentistry and Prosthodontics, Mosby Ltd., 2016:161-171.

7. Kondrat W, Sierpińska T, Gołębiewska M., Vibration analysis of temporomandibular joints - BioJVA device description and its clinical application in dental diagnostics - review of literature, Journal of Stomatology. 2012; 65(2): 207-215, Polish. 
8. Lis W, Salamon R, Zienkiewicz J. Studying the acoustic emission of the temporomandibular joint, Archives of Acoustics 1999; 24: 303-317.

9. Majewski S, Dental gynathophysiology, Warszawa, PZWL, 2007. Polish.

10. Matthew R. Hammer, Yassine Kanaan, Imaging of the Pediatric Temporomandibular Joint, Oral and Maxillofacial Surgery Clinics of North America, 2018; 30(1): 25-34. https://doi.org/10.1016/j.coms.2017.08.008

11. Mohammed AQ. Al-Saleh, Carlos Flores-Mir, Norman MR. The, Electromyography in diagnosing temporomandibular disorders, The Journal of the American Dental Association, 2012; 143(4): 351-362. https://doi.org/10.14219/jada.archive.2012.0177

12. Radke JC. The temporomandibular joint: the foundation of the masticatory system. Protetyka Stomatologiczna, 2012; LXII(5), 382-389, Polish.

13. Radlanski RJ, Wesker KH. FACE - atlas of clinical anatomy. Warszawa, Wydawnictwo Kwintesencja, 2015, Polish.

14. Richard W. Katzberg, William F. Conway, Susan J. Ackerman, Theresa S. Gonzales, Michael S. Cronan, Pilot Study to Show the Feasibility of HighResolution Sagittal Ultrasound Imaging of the Temporomandibular Joint, Journal of Oral and Maxillofacial Surgery, 2017; 75(6): 1151-1162. https://doi.org/10.1016/j.joms.2016.12.007

15. Tore A. Larheim, Caroline Hol, Margareth Kristensen Ottersen, Bjørn B. Mork-Knutsen, Linda Z. Arvidsson, The Role of Imaging in the Diagnosis of Temporomandibular Joint Pathology, Oral and Maxillofacial Surgery Clinics of North America, 2018; 30(3): 239-249.

https://doi.org/10.1016/j.coms.2018.04.001

\section{ACKNOWLEDGEMENTS}

The work was created as part of the statutory research project of Department of Mechanics and Vibroacoustics AGH in Krakow (project No. 11.11.130.734).

\section{Received 2018-05-02}

Accepted 2018-08-13

Available online 2018-09-03

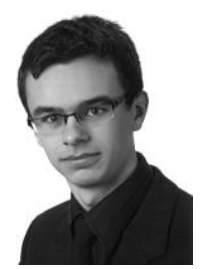

Pawel ŁYŻWA B.Sc. Eng. achieved his degree studying Acoustic Engineering at AGH University of Science and Technology in Kraków and continues his study at master programme there. He also graduated Music Production and Recording Techniques at University in Stavanger. His early research was focused on vibroacoustic methods of imaging in temporomadibular joint disorders. Currently he focuses on classical music recording and investigates perception of localization and depth in recordings with basic stereo techniques. Member of Audio Engineering Society (AES)

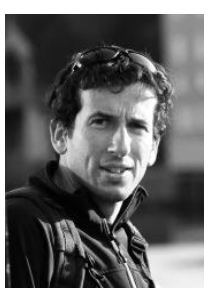

Maciej KŁACZYŃSKI Ph.D. D.Sc. Eng., works at Department of Mechanics and Vibroacoustics in AGH University of Science and Technology in Krakow. His research is focused on measurement, signal processing and pattern recognition methods of vibroacoustic signals applied in medicine, technology and environmental monitoring. Author of over one hundred scientific publications and conferences papers. Member of European Acoustics Association (EAA), Polish Acoustical Society (PTA) and Polish Society of Technical Diagnostics (PTDT).

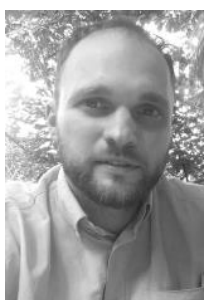

Piotr KAZANA, Master of physiotherapy, graduated at the Faculty of Health Sciences at Jagiellonian University Medical College. Since 2010 conducts his own clinical practice in a private office of dental physiotherapy. 